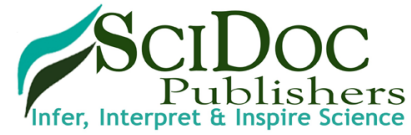

\section{A Comparison Of Topographic and Refractive Effects from Arcuate Incisions in Keratoplasty: Deep Anterior Lamellar Vs. Penetrating}

Research Article

\author{
Alshaarawy $\mathrm{AM}^{1,3 *}$, Ahmed $\mathrm{MH}^{2}$, Zaki AA ${ }^{1}$, Sayed Saif $\mathrm{MY}^{2}$, Terry $\mathrm{MA}^{3}$ \\ ${ }^{1}$ The Ophthalmology Department in Research Institute of Ophthalmology, Cairo, Egypt. \\ ${ }^{2}$ The Ophthalmology Department at Beni Suef University, Beni Suef, Egypt. \\ ${ }^{3}$ Devers Eye Institute, Portland, Oregon, USA.
}

\title{
Abstract
}

Purpose: To compare the topographic and refractive effects from the arcuate relaxing incisions in treating post-keratoplasty astigmatism after deep anterior lamellar keratoplasty (DALK), penetrating keratoplasty (PKP).

Setting: A one center study: Devers Eye Institute, Portland, Oregon, USA.

Design: Retrospective review of consecutive cases.

Methods: The study is divided into two groups: DALK and PKP group. Each group contains 20 eyes with residual astigmatism more than 4 Diopters (D) 3 months after full suture removal. Subjects underwent arcuate relaxing incision at $90 \%$ depth of the thinnest point at the steepest hemi-meridian. The corneal and refractive astigmatism, spherical equivalent, refraction and BCSVA were compared preoperative and 3 months postoperative.

Results: Topographic astigmatism improved by $3.5 \pm 3.18 \mathrm{D}$ in PKP, and $3.89 \pm 4.92 \mathrm{D}$ in DALK group ( $p$-value $=0.051)$, Refractive astigmatism improved in DALK group by $2.9 \pm 3.08 \mathrm{D}$ and in PKP by $1.6 \pm 2.64 \mathrm{D}$, $(p$-value $=0.163)$. The mean spherical equivalent changed by $-0.72 \pm 1.5 \mathrm{D}$ in PKP, and $-1.99 \pm 2.45 \mathrm{D}$ in DALK group, $(p$-value $=0.206)$. The Difference Vector in DALK group was $8.44 \pm 13.54 \mathrm{D}$, and in PKP, it was $4.7 \pm 2.12 \mathrm{D}$.

Conclusion: The arcuate relaxing incision is an effective procedure for reducing post-keratoplasty astigmatism. There was a variation of response that may be due to the biomechanics of the healed graft; future studies should be using a Femtosecond laser in an extensive series of eyes with equivalent levels of astigmatism. This may also allow for a lower, tighter range of effect in both groups.

Keywords: Arcuate Relaxing Incision; Arcuate Keratotomy (AK); Corneal Relaxing Incision (CRI); Keratoplasty; Astigmatism.

\section{Introduction}

Post-Keratoplasty astigmatism is a significant challenge for surgeons after a successful keratoplasty surgery. Many measures have been studied for its management; starting from simple measures such as contact lenses, Spectacles [1], Selective Suture Removal (SSR) in interrupted or mixed sutures, and Suture sliding in single continues sutures (SCS) $[2,3]$. Others include Wedge resection [4], Excimer LASER ablation either photorefractive keratectomy (PRK) with Intraoperative Mitomycin C (MMC) [5] or Laser-assisted in situ keratomileusis (LASIK) [6]. Moreover, wavefront-guided LASIK was effective in treating irregular astigmatism [7]. Toric Intraocular Lens (IOL) Implantation for correction of regular astigmatism [8], and finally repeat keratoplasty [9].

Penetrating keratoplasty (PKP) jeopardizes the intraocular anatomy and immunological integrity of the eye. Hence, it increases the risk of rejection and intraocular inflammation [10, 11]. Anwar et al., has described Deep Anterior Lamellar Keratoplasty (DALK) using the big-bubble technique as replacing only the stromal tissue and preserving recipient endothelium [12]. It has many advantages over PKP such as preservation of the globe integrity, faster

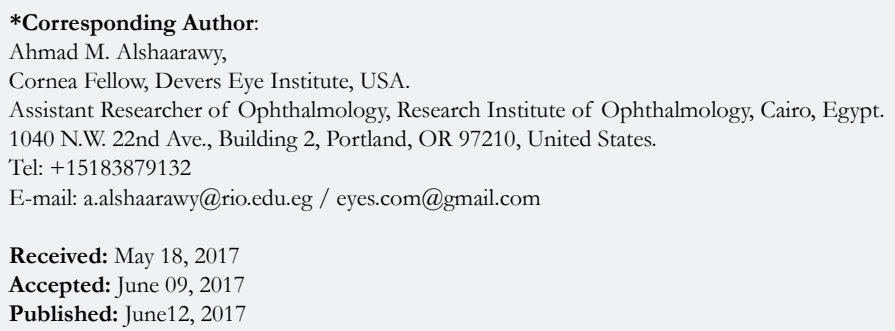

Citation: Alshaarawy AM, Ahmed MH, Zaki AA, Sayed Saif MY, Terry MA (2017) A Comparison Of Topographic and Refractive Effects from Arcuate Incisions in Keratoplasty: Deep Anterior Lamellar Vs. Penetrating. Int J Ophthalmol Eye Res. 5(6), 322-328. doi: http://dx.doi.org/10.19070/2332-290X-1700066

Copyright: Alshaarawy $\mathbf{A M}^{\circ}$ 2017. This is an open-access article distributed under the terms of the Creative Commons Attribution License, which permits unrestricted use, distribution and reproduction in any medium, provided the original author and source are credited. 
wound healing, earlier suture removal, faster visual rehabilitation, no risk of endothelial rejection and this leads to the rapid tapering of steroids and reduction of complications [13].

Arcuate Relaxing Incisions "Arcuate keratotomy" (AK) provides for fast visual rehabilitation, as well as economical, easy, and a relatively safe procedure for the management of post-keratoplasty astigmatism. It is defined as creating one or more arc-shaped incision in the cornea [14]; it can be constructed using the blade, arcuate Keratome [15] or Femtolaser [16]. Moreover, it can be combined with Excimer LASER [17], stress sutures [18], and during cataract surgery [19]. Its main principle is flattening of the steep meridian, and that will also steepen the opposite un-incised meridian that is 90 degrees away, which is known as the coupling ratio. The coupling ratio can be one where the flattening of the steep meridian and the steepening of the opposite meridian is equal, and that will not change the spherical equivalent. However, if the coupling ratio is more than one, then that will result in more flattening of the incised meridian than the steepening of the un-incised opposite meridian leading to more flattening of the cornea and the spherical equivalent will be a hyperopic shift, and vice versa [20]. We hypothesize that the tightness of the graft in DALK being pushed by the host Descemet's membrane might affect the outcome of the incision.

\section{Methods}

This study is a retrospective review of Interventional consecutive case series in a single-center, Devers Eye Institute, Portland, Oregon, USA. Surgical consent for AK surgery was approved by our hospitals' institutional review boards for patients. This study was divided into two groups: A DALK group and A PKP group, each group contains 20 eyes. We analyzed 40 consecutive eyes intervened upon at the Devers Eye Institute, cornea service in Portland, OR, USA. In the DALK group, only one patient was excluded, as there was an intraoperative wound gaping after the incision, which needed to be corrected by immediate suturing. All patients were adults and of any sex; three months after complete suture removal with astigmatism more than 4 Dioptres (D), all grafts were clear, central, with similar intraoperative trephination size, with no clinical edema at the slit-lamp examination. All patients have completed the follow-up visits, and the refractive and topographic data were recorded, preoperative and average 3 months' postoperative. We excluded patients with irregular astigmatism that prevented proper estimation of the refraction, severe dry eye, signs of allograft reaction, any active infectious disease, visually significant cataracts, pregnancy, and collagen disease.

\section{Technique}

We adopt the Moorfields Eye Hospital standardized AK technique [14]. The 6 O'clock position was marked while the patient is upright and looking straight ahead with both eyes open to avoid cyclotorsion. Under topical anesthesia, all eyes had at least one relaxing incision using a guarded, Thornton triple-edged arcuate blade (Duckworth \& Kent), which was set at 90\% depth of the thinnest point at the steepest hemi-meridian guided by the oculus Pentacam ${ }^{\circledR}$. The incision was placed $0.5 \mathrm{~mm}$ inside the donor's cornea for a 60-degree arc. After surgery, a topical antibiotic and steroids were prescribed. Postoperative follow-up examinations were performed on the first post-opertive day, at week 1, at months 1, 2, 3 and included: Manifest Refraction, Best spectacle-corrected visual acuity (BSCVA), Corneal topography, using the Oculus Pentacam ${ }^{\circledR}$. Moreover, other routine ophthalmological exams were conducted. Statistics: At the end of this study, data was statistically described in terms of mean \pm standard deviation $( \pm \mathrm{SD})$, median, correlation and percentages when appropriate, Comparison of numerical variables between the two study groups was made using Paired-Samples and Independent T-Test. In vector analysis, the data was not normally distributed, so the Mann-Whitney $U$ test was used as a test of significance. Correlation between groups using Pearson correlation: All statistical calculations were made using computer programs IBM $^{\circledR}$ SPSS $^{\circledR}$ Statistics Version 22 (Statistical Package for the Social Science; SPSS Inc., Chicago, IL, USA) for Macintosh. P-values less than 0.05 were considered significant.

\section{Results}

The mean topographic astigmatism change showed an improvement of $3.5 \pm 3.18 \mathrm{D}$ (from $8.56 \mathrm{D}$ to $4.78 \mathrm{D})$ in $\mathrm{PKP}(p$-value $=$ 0.01 ) and improvement of $3.89 \pm 4.92 \mathrm{D}$ (from 9.04 D to $5.15 \mathrm{D}$ ) in DALK group $(p$-value $=0.03)$ as shown in Table 1 and Figure 1 . The change in refractive astigmatism showed an improvement of $1.62 \pm 2.64 \mathrm{D}$ improvement in PKP group (from $4.73 \mathrm{D}$ to $2.88 \mathrm{D})(p$-value $=0.033)$ and improvement of $2.9 \pm 3.08 \mathrm{D}$ in DALK group (from $6.38 \mathrm{D}$ to $3.46 \mathrm{D})(p$-value $=0.01$ ) as shown in Table 2 and Figure 2.

The spherical equivalent showed, a change of $-0.72 \pm 1.5 \mathrm{D}$ in PKP group (from $-2.08 \mathrm{D}$ to $-2.95 \mathrm{D})(\phi$-value $=0.02)$, and a change of $-1.99 \pm 2.45 \mathrm{D}$ in DALK group (from $2.28 \mathrm{D}$ to -4.27 $\mathrm{D}(p$-value $=0.109)$ as shown in Table 3 and Figure 3.

The best spectacle corrected visual acuity (BSCVA) improved by $0.22 \pm 0.4$ logarithm of the minimal angle of resolution (LogMAR)(from 0.56 LogMAR to 0.35 LogMAR) $(p$-value $=0.039)$ "two lines gain" in PKP group, while in the DALK group it improved by $0.09 \pm 0.38$ LogMAR (from 0.5 LogMAR to 0.44 LogMAR) $(p$-value $=0.31)$ "one line gain" as shown in Table 4 and Figure 4. However, it should be noted that the vision is a secondary outcome measure in this study since the comorbidities that may affect the vision were not an exclusion factor for the study and there may have been more co-morbidities in the DALK than the PK group.

For Vector Analysis, all patients' data were calculated using the VECTrAK by ASSORT Pty. Ltd.; Version: 2.2.1. Target Induced Astigmatism (TIA) [21] was $9.03 \pm 3$ Din DALK compared to $8.34 \pm 3.4 \mathrm{D}$ in PKP group ( $p$-value $=0.026)$. Surgical Induced Astigmatism (SIA) [21] was 10.64 $\pm 4.53 \mathrm{D}$ in DALK group compared to $7.66 \pm 5.33 \mathrm{D}$ in $\mathrm{PKP}(\not$-value $=0.026)$ as shown in Figure 5 and Figure 6.

Difference Vector (DV) [21] was 8.44 \pm 13.54 D. In DALK group, $4.77 \pm 2.12 \mathrm{D}$ in PKP ( $p$-value $=0.415)$. Correction Index $(\mathrm{CI})$ [21] was $1.25 \pm 0.68$ (overcorrection) in DALK group and (under-correction) $0.9 \pm 0.62$ in PKP group $(p$-value $=0.056)$.

The magnitude of Error (MOE) [21] in the DALK group showed an overcorrection "a positive value" (1.60 \pm 4.42$)$, However in PKP it showed an under-correction "a negative value" (-0.67 \pm 
Table 1. Topographic Astigmatism Change in PKP, and DALK Group.

\begin{tabular}{|c|c|c|c|c|c|c|}
\hline \multicolumn{7}{|c|}{ Topographic Astigmatism Change, $\boldsymbol{p}$ - value $=\mathbf{0 . 0 5 1}$} \\
\hline & Mean & Standard Deviation & Median & Minimum & Maximum & $\boldsymbol{p}$ - value \\
\hline PKP & -3.56 & 3.18 & -3.29 & -9.04 & 2.4 & 0.01 \\
\hline DALK & -3.89 & 4.92 & -3.82 & -11 & 5.97 & 0.03 \\
\hline
\end{tabular}

Figure 1. Mean Topographic Astigmatism Change in PKP and DALK.



Table 2. Refractive Astigmatism Change in PKP and DALK group.

\begin{tabular}{|c|c|c|c|c|c|c|}
\hline \multicolumn{7}{|c|}{ Refractive Astigmatism change, $\boldsymbol{p}$ - value $=\mathbf{0 . 1 6 3}$} \\
\hline & Mean & Standard Deviation & Median & Minimum & Maximum & $\boldsymbol{p}$ - value \\
\hline PKP & -1.62 & 2.64 & -2.5 & -4.75 & 4.75 & 0.033 \\
\hline DALK & -2.92 & 3.08 & -4.5 & -7.75 & 2 & 0.01 \\
\hline
\end{tabular}

Figure 2. Mean Refractive Astigmatism Change in PKP and DALK, Showing more Change in DALK group.

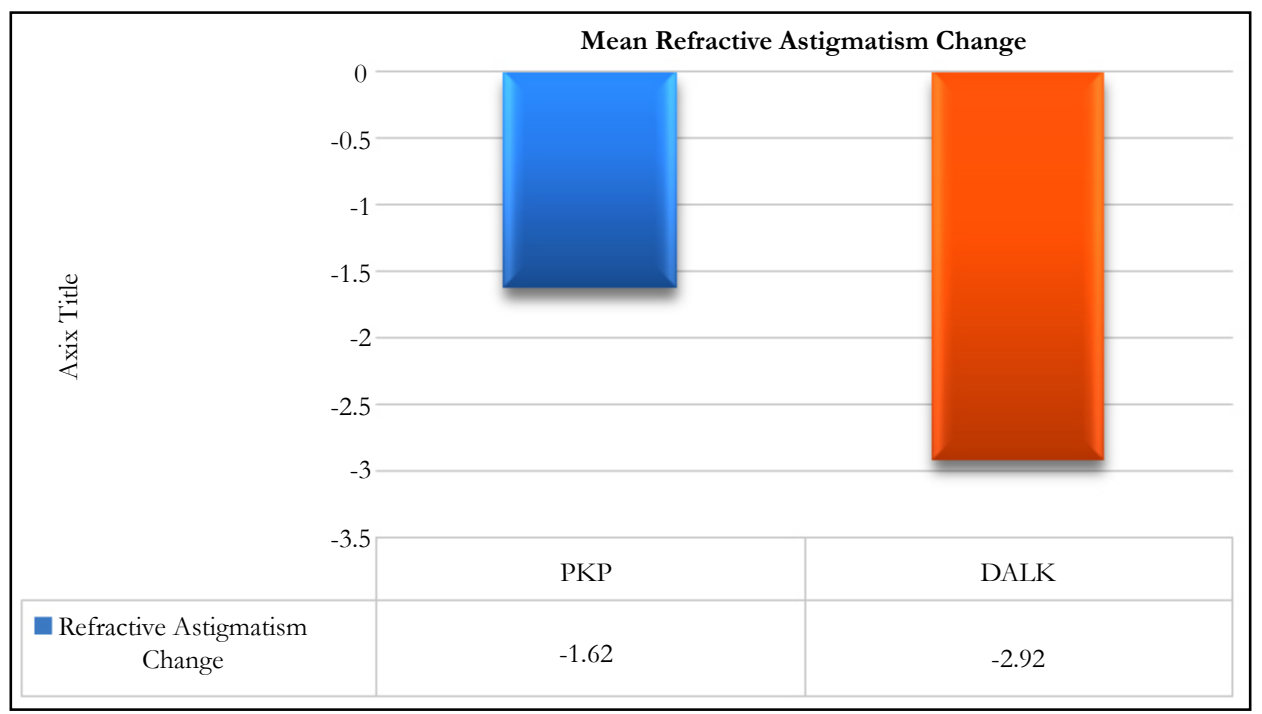

4.39) $(p$-value $=0.056)$. The angle of Error $(\mathrm{AOE})[21]$ in DALK $(5 \pm 15(p$-value $=0.855)$ and in PKP $(4 \pm 12)(p$-value $=0.056)$. Therefore, the treatment in both groups was counter-clockwise (CCW) to the intended axis of correction, but it was more so in the DALK group. Index of Success (IOS) [21] in both groups showed very close results, in the DALK group it was $(0.68 \pm$ $0.61)$, and in PKP it was $(0.64 \pm 0.36)(p$-value $=0.725)$. Flattening
Effect (FE) [21] in the DALK group, it showed $(9.61 \pm 4.87)$ and in PKP group it showed $(9.06 \pm 9.89)(p$-value $=0.725)$. Flattening index (FI) [21] in the DALK group led to more flattening (1.1 $\pm 0.65)$, than in PKP where it was $(0.85 \pm 0.52)(p$-value $=0.119)$. Torque [21] in both groups was a positive value "lying 45 degrees CCW to SIA"; in the DALK group, it was $(3.1 \pm 2.8)$, but in the PKP group, it was $(2.36 \pm 2.02)(p$-value $=0.201)$. 
Table 3. Spherical Equivalent change in PKP and DALK group.

\begin{tabular}{|c|c|c|c|c|c|c|}
\hline \multicolumn{7}{|c|}{ Spherical Equivalent change, $p$-value $=\mathbf{0 . 2 0 6}$} \\
\hline & Mean & Standard Deviation & Median & Minimum & Maximum & $p$-value \\
\hline PKP & -0.72 & 1.5 & -0.88 & -3.13 & 1.75 & 0.02 \\
\hline DALK & -1.99 & 2.45 & -2.13 & -6 & 3.75 & 0.109 \\
\hline
\end{tabular}

Figure 3. Mean Spherical Equivalent Change, Coupling Ratio is less than 1, Showing a Myopic Shift more in DALK than PKP.

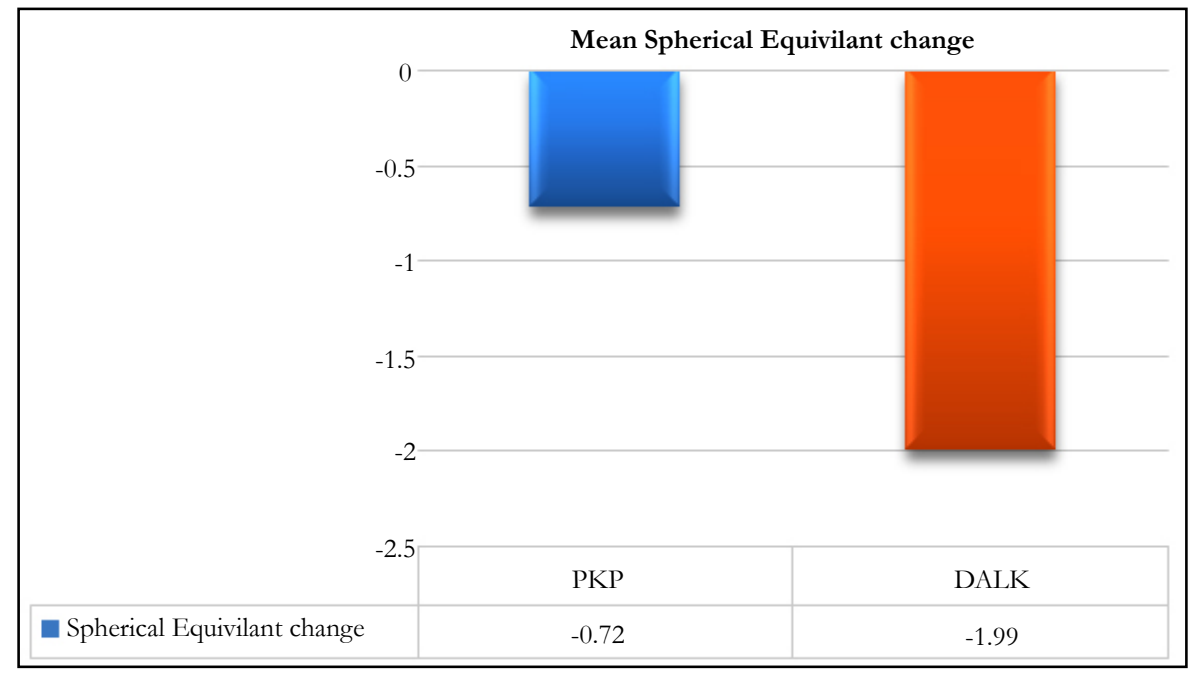

Table 4. BCSVA "LogMAR" Change in PKP, DALK.

\begin{tabular}{|c|c|c|c|c|c|c|}
\hline \multicolumn{7}{|c|}{ BCVA change (LogMAR), $\boldsymbol{p}$-value $=\mathbf{0 . 6 1 4}$} \\
\hline & Mean & Standard Deviation & Median & Maximum & Minimum & $\boldsymbol{p}$-value \\
\hline PKP & -0.22 & 0.4 & -0.11 & -1.18 & 0.4 & 0.039 \\
\hline DALK & -0.09 & 0.38 & -0.13 & -0.7 & 1 & 0.312 \\
\hline
\end{tabular}

Figure 4. Mean BCSVA change (LogMAR) in PKP and DALK.

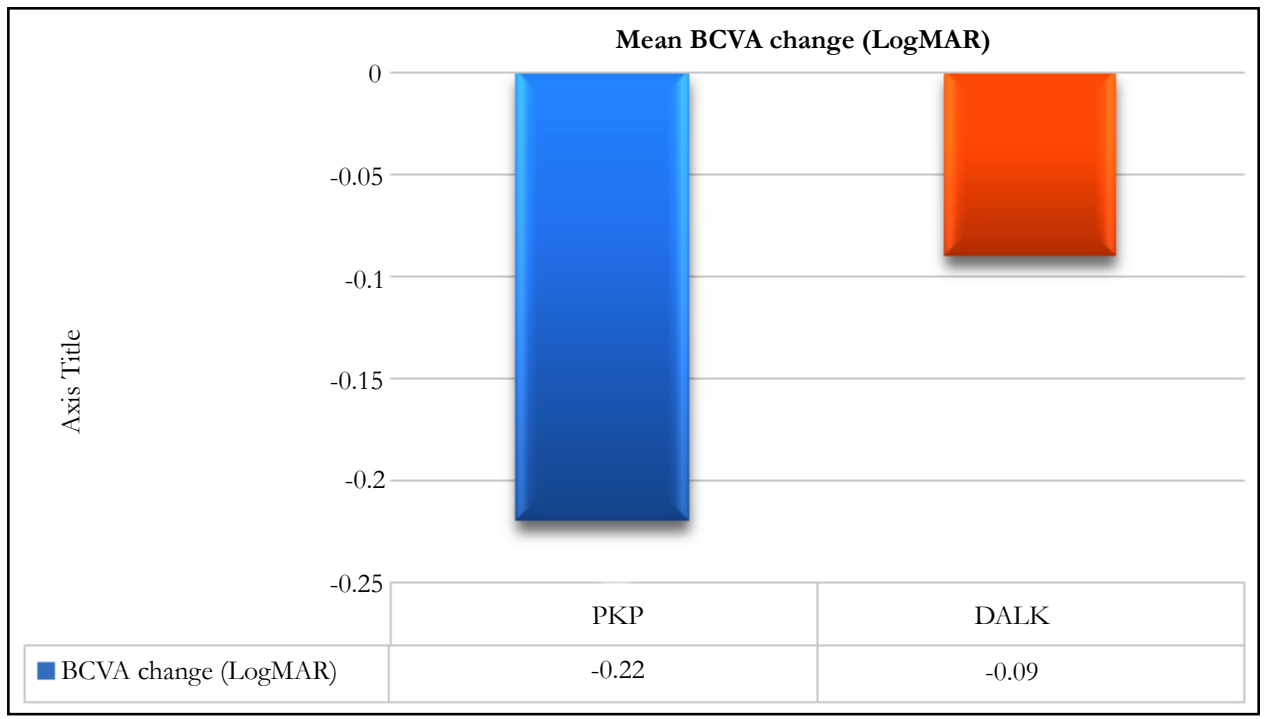

\section{Discussion}

Postoperative keratoplasty astigmatism is considered one of the limiting factors of visual quality after keratoplasty. High postoperative astigmatism can compromise the patient's return to normal binocular vision. Anisometropia may result in a headache, photophobia, burning, tearing, diplopia, and blurred vision, resulting in an impact on the quality of the patient's life and a substantial economic burden, "especially due to the high cost of the keratoplasty". The arcuate relaxing incision is considered an effective, simple method of reducing astigmatism after keratoplasty. We hypothesize that the graft in DALK being pushed by the host Descemet's membrane might affect the outcome of the arcuate incision. 
Figure 5. Target Induced Astigmatism vs. Surgically Induced Astigmatism in PKP.

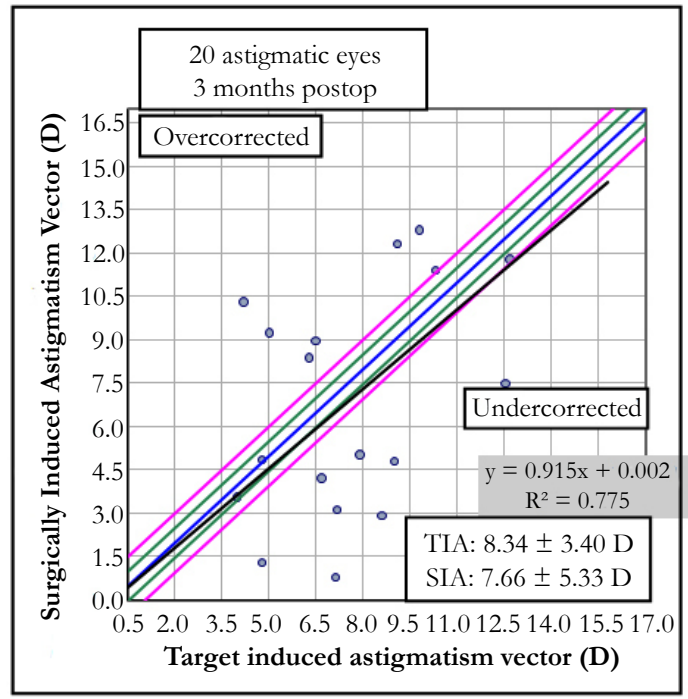

Figure 6. Target Induced Astigmatism vs. Surgically Induced Astigmatism in DALK.



In the Visual Acuity, our Study showed an improvement of 0.22 (LogMAR) "gain of two lines" in the PKP group ( $p$-value $=0.03)$, and a little improvement of 0.09 (LogMAR) "almost gain of one line" in the DALK group ( $p$-value $=0.31$ ). Kubaloglu et al., studied the arcuate incision to compare the astigmatism treatment in 20 DALK patients vs. 24 PKP patients, and their results showed similar results to ours, where the improvement in vision was more in PKP from $(0.13 \pm 0.08)$ to $(0.11 \pm 0.08)$ with a gain of 1.1 lines in the PKP ( $p$-value $=0.01)$. And almost no improvement of $(0.16$ $\pm 0.09)$ to $(0.16 \pm 0.12)$ with gain of 0.6 lines in the DALK group $(p$-value $=0.13)$ [22]. Loriaut et al., studied the arcuate incision using the Femtosecond laser in 20 patients and their results showed an improvement in vision from 0.5 to $0.3(p$-value $=0.49)$ [23].

The mean preoperative topographic astigmatism was almost the same in both groups, it was $8.56 \mathrm{D}$ improved to $4.78 \mathrm{D}$; a 3.5 $\mathrm{D}$ change $(41.4 \%$ improvement $)$ in PKP group $(p$-value $=0.01)$; and $9.04 \mathrm{D}$ that improved to $5.15 \mathrm{D}$; a $3.89 \mathrm{D}$ change $(43 \% \mathrm{im}-$ provement) in DALK group ( $p$-value $=0.03)$. Kubaloglu et al.,'s topographic astigmatism change was $3.27 \mathrm{D}(p=0.2)$ in DALK, and 4.27 D $(p=0.2)$ in PKP [22]. We had similar results as Kubaloglu et al., in their DALK group as it was $7.4 \mathrm{D}$ improved to 4.24
D (42\% improvement); however, in their PKP group, it was 7.92 $\mathrm{D}$ improved to $3.73 \mathrm{D}(52 \%)$ [22]. Our results showed almost the same improvement of topographic astigmatism in DALK and PKP groups, the higher preoperative astigmatism we had in PKP group than their group can explain that.

In Loriaut et al.,'s study [23], the mean topographic astigmatism decreased from $9.45 \mathrm{D}$ to $4.64 \mathrm{D}(P=0.001)$, meaning they showed a $50 \%$ improvement, which was slightly better than our study and almost the same as Kubaloglu et al.,'s study [22].

In our study, the mean Preoperative refractive astigmatism was 4.73 D improved to $2.88 \mathrm{D}$ in PKP group and $6.38 \mathrm{D}$ which improved to $3.46 \mathrm{D}$ in the DALK group. The mean refractive astigmatism change showed an improvement of $1.6 \mathrm{D}(34 \%)$ in $\operatorname{PKP}(p$-value $=0.03)$ and an improvement of $2.9 \mathrm{D}(45.4 \%)$ in DALK group $(p$-value $=0.01)$. In Kubaloglu et al.,'s study [22], the decrease in the refractive cylinder was $43 \%$ DALK group and $52 \%$ in the PK group, they also showed a change in refractive astigmatism from $6.24 \mathrm{D}$ to $3.53 \mathrm{D}(43 \%)$ in the DALK group $(P$ $=0.001)$ and from $6.48 \mathrm{D}$ to $3.31 \mathrm{D}(53 \%)$ in the PK group $(P=$ $0.001)[22]$. 
In our study, the improvement was more for the DALK group, results were statistically insignificant $(\phi$-value $=0.163$ ), and that aligned with the results of Kubaloglu et al., study [22]. In Loriaut et al.,'s study [23], the mean Preoperative refractive astigmatism decreased by $3.79 \mathrm{D} \pm 2.06 \mathrm{D}$.

In our study, the mean spherical equivalent was a change of -0.72 $\mathrm{D}$ (from -2.08 D to $-2.95 \mathrm{D})$ in PKP group $(p$-value $=0.02)$ and a change of $-1.99 \mathrm{D}$ (from $-2.28 \mathrm{D}$ to $-4.27 \mathrm{D}$ ) in the DALK group $(p$-value $=0.109)$. The coupling ratio in both groups was less than one, the PKP group showed a less myopic shift of $-0.7 \mathrm{D}$ than the DALK group, which was $-1.99 \mathrm{D}(p$-value $=0.206)$.

In Kubaloglu et al.,'s study [22], The mean spherical equivalent decreased from $-4.53 \mathrm{D}$ to $-2.94 \mathrm{D}(P=.001)$ in the DALK group and from $-5.29 \mathrm{D}$ to $-3.11 \mathrm{D}(P=.001)$ in the PKP group. Their coupling ratio was more than one (a hyperopic shift). In Loriaut et al.,'s study [23], the mean spherical equivalent was -4.34 $\mathrm{D}$ changed to $-4.44 \mathrm{D}$, showing a myopic shift just as our results showed.

\section{Vector Analysis}

Correction Index (CI): In our study, there was overcorrection (1.25) in the DALK group and undercorrection (0.85) in the PKP group, $(\not$-value $=0.05)$. In Kubaloglu et al.,'s study [22] their results were 0.97 in DALK group and 1.16 in PKP group, showing the opposite of our results where the overcorrection was in PKP group. However, their results were statistically insignificant ( $\phi$-value $=0.32$.

In Loriaut et al.,'s study [23], it was 0.9 where there was a 0.1 undercorrection.

Difference Vector (DV): In our study, in the DALK group it was (8.44) and in PKP it was (4.5) ( $p$-value $=0.415)$. In Kubaloglu et al.,'s study [22], their result in the DALK group was (4.72) and in PKP it was $(6.1)(p$-value $=0.98)$.

Our results showed a better improvement in the PKP group compared to the DALK group than their results. That is because we had a higher pre-operative astigmatism in our data than their data. However, both our results and theirs were statistically insignificant.

Magnitude of Error (MOE): In our data in DALK group, it showed an overcorrection "a positive value" (1.60). However, in PKP, it showed an undercorrection "a negative value" $(-0.79)$.

We were different from the Kubaloglu et al.,'s study [22] in the DALK group, where we showed an overcorrection and they showed an undercorrection, and we both showed an undercorrection in PKP group. Both our results and their results were statistically insignificant.

Angle of Error (AOE): In our results, in both groups, there was a positive value so the treatment in both groups was counter-clockwise $(\mathrm{CCW})$ to the intended axis of correction, but it was more so in the DALK group $(p$-value $=0.855)$, whereas in the DALK group it was 5, which is comparable to Kubaloglu et al.,'s study [22] (they showed 5.7). However, in PKP it was [4], but their results were a negative value $(-4.75)$. Both our results and their results were statistically insignificant.

Index of Success (IOS): In our study, in the DALK group, it was (0.68) and in Kubaloglu et al.,'s study [22], it was (0.7), but in PKP it was (0.64) and (0.8) in their group. Both our results and their results were statistically insignificant.

Flattening Index (FI): In our study, in the DALK group, it leads to more flattening (1.1) than in PKP where it was (0.85) ( $p$-value $=0.119)$.

In Kubaloglu et al.'s study [22], in the DALK group, it leads to more flattening (0.7) than in PKP where it was (0.6), just like our results. Both our results and their results were statistically insignificant.

Torque: In both studies, it was a positive value "lying 45 degrees CCW to SIA". In our DALK study group, it was (3.1) and in Kubaloglu et al.,'s study [22] it was (2.7), and in our PKP study group it was (2.2) and (1.7) in their study.

The arcuate relaxing incision is considered an efficient and safe procedure in reducing the postoperative keratoplasty astigmatism and improving the best-corrected visual acuity. In our study, there was an overcorrection in the DALK group more than the PKP group. The rotation of treatment (Torque) was more so in the DALK group, which may be explained by the difference in biomechanics between both of them, as the DALK graft is under the tension of the host Descemet's membrane, which might exaggerate the arcuate relaxing incision effect.

There was a variation of response to our surgery of relaxing incisions, and that may be due to the biomechanics of the healed PKP or DALK, which have extreme variation in biomechanical stress lines, with some steep meridians very responsive to arcuate incisions and others less so.

The variability also can be explained by:

1 - The retrospective case series.

2 - Mechanical incisions made leading to a) variation in achieving the actual $90 \%$ depth we sought b) variation in the verticality of the incisions (i.e., not always possible to know that the incisions were placed perfectly perpendicular to the surface of the cornea c) variation of length of incisions.

3 - Number of incisions varied: some of the cases got one incision, others got two depending on what was found by the operating keratometer and the effect after the first incision was made.

4 - Variation in the preoperative astigmatism of cases: A Moorfields study showed that the higher astigmatism, the greater the effect of the same number and length of relaxing incisions [14]. That it was the biomechanical stress variation that determined the effect of the relaxing incision, less than the relaxing incisions themselves.

5-A Relative low number of cases for analysis, and with this much variability, it is hard to draw conclusions.

Femtosecond laser arcuate keratotomy showed a comparable re- 
sult to our study, but it might be safer than the manual arcuate relaxing incision due to the accuracy of the depth and the reproducibility of the results decreasing the human error.

Further studies can suggest a Nomogram for arcuate incision treatment in DALK and PKP using the Alpins method to avoid the overcorrection and the torque that was noticed in DALK group. Future studies should be using a Femtosecond laser with standard settings for both PKP and DALK in a large series of eyes with equivalent levels of astigmatism. This may also allow for a lower, tighter range of effect in both groups.

\section{What was Known}

Arcuate relaxing incision provides a safe method for reducing post keratoplasty astigmatism with no enough data that compares it in DALK versus PKP.

\section{What this Paper Adds}

In our study, it showed a difference in the outcome between DALK, and PKP which might be attributed to the difference in the biomechanics, and that will need further studies to support this conclusion.

\section{References}

[1]. Riddle HK, Parker DAS, Price FW (1998) Management of post-keratoplasty astigmatism. Curr Opin Ophthalmol. 9(4): 15-28. doi:10.1097/00055735199808000-00004.

[2]. Van Meter WS, Gussler JR, Soloman KD, Wood TO (1991) Postkeratoplasty Astigmatism Control. Ophthalmology. Single continuous suture adjustment versus selective interrupted suture removal. 98(2): 177-183. doi:10.1016/S0161-6420(91)32319-4.

[3]. Hope-Ross MW, McDonnell PJ, Corridan PG, Naylor G, Tan-Yee A (1993) The management of post-keratoplasty astigmatism by post-operative adjustment of a single continuous suture. Eye (Lond). 7 (5): 625-628. doi:10.1038/ eye.1993.144.

[4]. de la Paz MF, Sibila GR, Montenegro G, de Toleda JA, Barraquer R, et al., Wedge resection for high astigmatism after penetrating keratoplasty for keratoconus: refractive and histopathologic changes. Cornea. 29(6): 595-600. doi:10.1097/ICO.0b013e3181ba0abf.

[5]. Forseto ADS, Marques JC, Nosé W (2010) Photorefractive keratectomy with mitomycin $\mathrm{C}$ after penetrating and lamellar keratoplasty. Cornea. 29(10): 1103-1108. doi:10.1097/ICO.0b013e3181d0fecd.

[6]. Buzard K, Febbraro J-L, Fundingsland BR (2004) Laser in situ keratomileusis for the correction of residual ametropia after penetrating keratoplasty. J Cataract Refract Surg. 30(5): 1006-1013. doi:10.1016/j.jcrs.2003.08.035.
[7]. Imamoglu S, Kaya V, Oral D, Perente I, Basarir B, et al., (2014) Corneal wavefront-guided customized laser in situ keratomileusis after penetrating keratoplasty. J Cataract Refract Surg. 40(5): 785-792. doi:10.1016/j. jcrs.2013.10.042.

[8]. Coscarelli S, Ferrara G, Alfonso JF, Ferrara P, Lyra AP, et al., (2012) Intrastromal corneal ring segment implantation to correct astigmatism after penetrating keratoplasty. J Cataract Refract Surg. 38(6): 1006-1013. doi:10.1016/j. jcrs.2011.12.037.

[9]. Szentmáry N, Seitz B, Langenbucher A, Naumann GOH (2005) Repeat keratoplasty for correction of high or irregular postkeratoplasty astigmatism in clear corneal grafts. Am J Ophthalmol. 139(5): 826-830. doi:10.1016/j. ajo.2004.12.008.

[10]. Terry MA (2000) The evolution of lamellar grafting techniques over twentyfive years. Cornea. 19(5): 611-616.

[11]. Morris E, Kirwan JF, Sujatha S, Rostron CK (1998) Corneal endothelial specular microscopy following deep lamellar keratoplasty with lyophilised tissue. Eye (Lond). 12(4): 619-622. doi:10.1038/eye.1998.155.

[12]. Anwar M, Teichmann KD (2002) Big-bubble technique to bare Descemet's membrane in anterior lamellar keratoplasty. J Cataract Refract Surg. 28(3): 398-403. doi:10.1016/S0886-3350(01)01181-6.

[13]. El-Danasoury A (2013) Big bubble deep anterior lamellar keratoplasty (BB-DALK). Int Ophthalmol Clin. 53(1): 41-53. doi:10.1097/ IIO.0b013e3182713434.

[14]. Wilkins MR, Mehta JS, Larkin DFP (2005) Standardized arcuate keratotomy for postkeratoplasty astigmatism. J Cataract Refract Surg. 31(2): 297 301. doi:10.1016/j.jcrs.2004.07.025.

[15]. Hanna KD, Hayward JM, Hagen KB, Simon G, Parel JM, et al., (1993) Keratotomy for astigmatism using an arcuate keratome. Arch Ophthalmol. 111(7):998-1004.

[16]. Kymionis GD, Yoo SH, Ide T, Culbertson WW (2009) Femtosecond-assisted astigmatic keratotomy for post-keratoplasty irregular astigmatism. J Cataract Refract Surg. 35(1): 11-13. doi:10.1016/j.jcrs.2008.08.039.

[17]. Lipshitz I, Loewenstein A, Lazar M (1994) Astigmatic keratotomy followed by photorefractive keratectomy in the treatment of compound myopic astigmatism. J Refract Corneal Surg. 10(2): S282-4.

[18]. Koffler BH, Smith VM (1996) Corneal topography, arcuate keratotomy, and compression sutures for astigmatism after penetrating keratoplasty. J Refract Surg. 12(2): S306-S309.

[19]. Poll JT, Wang L, Koch DD, Weikert MP (2011) Correction of astigmatism during cataract surgery: toric intraocular lens compared to peripheral corneal relaxing incisions. J Refract Surg. 27(3): 165-171. doi:10.3928/10815 97X-20100526-01.

[20]. Faktorovich EG, Maloney RK, Price FW (1999) Effect of astigmatic keratotomy on spherical equivalent: results of the Astigmatism Reduction Clinical Trial. Am J Ophthalmol. 127(3): 260-269.

[21]. Alpins NA (1993) A new method of analyzing vectors for changes in astigmatism. J Cataract Refract Surg. 19(4): 524-533. doi:10.1016/S08863350(13)80617-7.

[22]. Kubaloglu A, Coskun E, Sari ES, Gunes AS, Cinar Y, et al., (2011) Comparison of astigmatic keratotomy results in deep anterior lamellar keratoplasty and penetrating keratoplasty in keratoconus. Am J Ophthalmol. 151(4): 637-643.e1. doi:10.1016/j.ajo.2010.10.029.

[23]. Loriaut P, Borderie VM, Laroche L (2015) Femtosecond-Assisted Arcuate Keratotomy for the Correction of Postkeratoplasty Astigmatism : Vector Analysis and Accuracy of Laser Incisions. Cornea. 34(9): 1063-1066. 